SHS Web of Conferences 24, 01004 (2016)

DOI: $10.1051 /$ shsconf/20162401004

(C) Owned by the authors, published by EDP Sciences, 2016

\title{
Understanding the online channel extension of traditional retailers: Online-offline and online-prototypical congruence
}

\author{
Jinfeng $\mathrm{Wu}^{*} \&$ Yilong Li \\ School of Management, Wuhan Textile University, Wuhan, Hubei, China
}

\begin{abstract}
Many Chinese traditional retailers have turned to the multichannel forms by establishing their own online stores. When doing so, retail managers face a difficult choice between two online marketing orientations: "pursuit of ideal" (i.e. online-prototypical congruence orientation) and "retention of tradition" (i.e. online-offline congruence orientation). To help managers make this choice, this study proposes a conceptual framework to illustrate how these two orientations affect retail store attitude when retail brand familiarity differs. The results indicate that both orientations can improve consumers' retail store attitudes. When retail brand familiarity is low, the online stores of traditional retailers should balance both orientations in product selections and adopt "pursuit of ideal" in prices. When retail brand familiarity is high, "retention of tradition" should be applied in product selections and both orientations should be integrated in prices for gaining more positive change in retail store attitude.
\end{abstract}

Keywords: multichannel retailing; online channel extension; retail store attitude; price congruence; product selection congruence; retail brand familiarity

\section{INTRODUCTION}

In recent years, Internet retailing has been growing steadily on the strength of rapidly evolving consumer shopping habits and game-changing retail technology. Increasingly, existing clients of physical stores are shifting to online shopping, who are driven by superior selection, lower prices and even greater convenience ${ }^{[1]}$. Traditional retailers are therefore forced to turn to a multichannel method by establishing their own online stores, which is also called as online channel extension. As the main way of traditional retailers to compete with pure e-tailers, online channel extension has grown tremendously, and it is expected to grow even further ${ }^{[2]}$.

In the process of the online channel extension, traditional retailers should adopt appropriate online marketing strategies to wield advantages of their brands and online stores. Observed from the relationships between online and physical stores of traditional retailers as well as benchmarks of online stores, two orientations of online marketing strategies have drawn our attention, that is, "pursuit of ideal"

*Corresponding author: fastwind75@163.com and "retention of tradition." "Pursuit of ideal" means that multichannel retailers take the ideal (prototypical) online stores as benchmarks and thus provide online product selections and prices similar to those of prototypical online stores (i.e. online-prototypical congruence orientation). To be competitive, multichannel retailers must make sure that their online stores possess requisite points of parity with prototypical online stores ${ }^{[3]}$. These requisite points are represented by product selections and price levels when multichannel retailers adopt "pursuit of ideal." Thus, the "pursuit of ideal" seems to be growing in importance to customers looking for low prices and wide product selections in online shopping. "Retention of tradition" refers to the fact that multichannel retailers keep their online product selections and prices consistent with those of their traditional (physical) stores (i.e. online-offline congruence orientation). Replicating salient and relevant associations of physical stores in online environment is crucial for the success of the online channel extension and the overall performance of the retailer ${ }^{[4]}$. When retailers adopt the "retention of tradition", product selection and price associations of physical stores are replicated online. Thus, the 
"retention of tradition" seems to remain to be important, because many customers prefer a traditional retailer's online store that provides offline products and do not want to be confused by inconsistent prices across channels ${ }^{[5]}$. Thus, both orientations could be effective depending on the customers' characteristics. In light of this, a key question is which orientation to emphasize and when to emphasize it to improve traditional retailers' operating performance.

As Badrinarayanan et al. [3] supposed, the effectiveness of both orientations may be constrained by characteristics of customers. Existing literature indicates that the retail brand familiarity is an important psychographic variable that influences consumers' attitudes toward the brand ${ }^{[6,7]}$. It is proved that the congruent information of new brand extension will cause a more positive feedback effect (i.e. positive brand attitude change) to the parent brand when brand familiarity is high rather than low $[8,9]$. Furthermore, secondary brand associations may be important to the formation of brand attitude if existing primary associations are deficient ${ }^{[10]}$, which is the case when the brand familiarity is low ${ }^{[7]}$. In our study, the "retention of tradition" signifies congruent information of retailers' brand extension from offline to online context. "Pursuit of ideal" implies transference of category attribute associations as secondary brand associations from a prototypical online store to the multichannel retailer. Therefore, the retail brand familiarity should be a telling moderator constraining the effectiveness of online marketing orientations. Based on this moderator, the customers of a retailer may be divided into two segment markets: customers with high familiarity and customers with low familiarity. Accordingly, retail managers may design different programs for each segment market.

To the best of our knowledge, however, no study has investigated which online marketing orientation is the best to target among customers with high or low retail brand familiarity. When should traditional retailers emphasize "pursuit of ideal" and when should they pertain to "retention of tradition"? Thus, our study has two research objectives: (1) Understand the implications and the relative impact of different online marketing orientations (the pursuit of ideal vs. the retention of tradition) on retail store attitude change; (2) perceive how the effects of both online marketing orientations on retail store attitude vary across customers with different degrees of the retail brand familiarity. From a practical standpoint, this study offers insights on how traditional retailers could improve consumers' retail store attitudes by managing the online channel extension. From a theoretical standpoint, the study advances knowledge regarding the change of retail store attitude in multichannel environment by integrating insights from multichannel retailing, brand equity and brand extension literatures.

\section{THEORETICAL BACKGROUND AND HYPOTHESES}

\subsection{Main effects of online marketing orientations on the retail store attitude change}

Mirroring the Schiffman and Kanuk's ${ }^{[11]}$ definition of attitude, we define retail store attitude as "a learned predisposition to behave in a consistently favourable or unfavourable way with respect to a retailer," which represents consumers' overall evaluations of a retail brand ${ }^{[12]}$. According to Spears and Singh ${ }^{[13]}$, attitude toward the retail brand is an internal and relative enduring state that endures for at least a short period of time and presumably energizes and directs behaviour. In the multichannel retail context, consumers held associations of retail brand attributes. The retail store attitude is formed on the basis of these associations since "brand attitudes are a function of the associated attributes and benefits that are salient for the brand" ${ }^{[10]}$. In order to eliminate the "noises" that other factors affecting the retail store attitude may impose on our conceptual model test, this study uses the "retail store attitude change" (i.e. the difference in the level of the retail store attitude between after and before online channel extension) instead of "retail store attitude" according to the suggestion of Dwivedi et al. ${ }^{[14]}$.

Customer-based brand equity theory ${ }^{[10]}$ indicates that the congruence of brand associations should affect: (1) how easily an existing associations can be recalled; (2) how easily additional associations can become linked to the brand node in memory. In other words, the congruence between new and existing brand attribute associations may strengthen both types of brand associations (new and existing associations) and thus boost the strength of brand beliefs. Additionally, consumers form brand image based on overall perceptions of all brand associations in their minds, which encompasses two components: brand beliefs and brand attitude ${ }^{[10,15]}$. The congruence among brand associations determines the "cohesiveness" of the brand image, that is, the extent to which the brand image is characterized by associations that share meaning ${ }^{[10]}$. Therefore, the congruence between new and existing brand attribute associations may enhance the uniqueness of brand beliefs. Furthermore, both uniqueness and strength are key dimensions indicating the level of brand beliefs ${ }^{[10,15]}$. Thus, the congruence between new and existing brand attribute associations may alter the level of brand beliefs by boosting their strength and uniqueness, which leads to change in consumers' overall evaluations on the brand (i.e. brand attitudes). Applying this theory to the current context, the congruence of product selection and price between online and offline stores (new and existing 
retail brand attribute associations) may cause change in consumers' attitudes toward the retail brand by altering the strength and uniqueness of retail brand beliefs. In other words, online-offline congruence orientation enables consumers to hold strong and unique beliefs toward the retail brand, which leads to more retail store attitude change.

Hla More retail store attitude change will be generated in response to product selection congruence between a traditional retailer's online and offline stores.

$H 1 b$ More retail store attitude change will be generated in response to price congruence between a traditional retailer's online and offline stores.

Keller ${ }^{[10]}$ proposed that because the brand is linked to the product category, some product category associations may be indirectly linked to the brand and become a part of brand associations. These brand associations belong to secondary associations of the brand. Secondary associations may lead to a transfer of attribute associations from another entity to the brand. In context of this study, attribute associations derived from online store category may be linked to the retail brand and thus become secondary associations ${ }^{[16]}$. Prototypical online stores possess a fuzzy set of category attribute associations that best represent the category ${ }^{[3]}$. These category attribute associations may be transferred to the retail brand as secondary associations and promote the favorability of retail brand beliefs, thus boosting the positive change of retail store attitude (i.e. transference effect of the prototypical online store). Furthermore, research on categorization theory suggests that prototypes allow individuals to group objects into categories, making it easier for them to judge a new stimulus ${ }^{[17]}$. According to the categorization approach of information processing, if a new stimulus can be categorized as an example of a previously defined category, then the associations related to the category can be quickly retrieved and applied to the stimulus ${ }^{[3]}$. Applying this theory to the current context, the better the congruence of product selections and prices between a traditional retailer's online store and a prototypical online store is, the easier the traditional retailer's online store to categorize as an example of online store category represented by the prototypical online store is, and the more complete the attribute associations transference from the prototypical online store is. In other words, online-prototypical congruence orientation may strengthen the transference effect of the prototypical online store, which in turn promotes the favorability of retail brand beliefs and eventually results in more positive change of retail store attitude.

H2a More retail store attitude change will be generated in response to product selection congruence between a traditional retailer's online and a prototypical online store.

$\mathrm{H} 2 \mathrm{~b}$ More retail store attitude change will be generated in response to price congruence between a traditional retailer's online and a prototypical online store.

\subsection{Moderating effects of retail brand familiarity}

The retail brand familiarity has important implications for consumer information processing and has been shown to be an important contingency factor for the success of channel extension strategies and activities. The retail brand familiarity reflects the extent of a consumer's direct and indirect experience with a retail brand ${ }^{[10]}$, which provides consumers with a richer, more detailed representation of a store in memory and a greater knowledge about the characteristics and criteria that differentiate it from competitors ${ }^{[18]}$.

According to the research of Thorbjørnsen ${ }^{[8]}$ in brand extension, high motivation to process congruent information conveyed by new brand extension is often presented when consumer is familiar with the brand. In this situation, consumers will process congruent information elaborately and piecemeal, which in turn further polarizes the strength and uniqueness of parent brand beliefs. Conversely, when brand familiarity is low, consumers are less motivated to process congruent information about new brand extension. In this situation, consumers do not engage in the cognitive elaboration when processing congruent information about the new brand extension. Accordingly, the strength and uniqueness of brand beliefs are less likely to be promoted. Applying this theory to the current context, consumers with high retail brand familiarity are more likely to deeply process online product selection and price information (new information about retail channel extension) which is congruent with that of offline channel (existing information about parent retail brand). The process will polarize the strength and uniqueness of the retail brand beliefs, thus leading to more change in retail store attitude. Conversely, when the retail brand familiarity is low, consumers are less likely to engage in cognitive elaboration about product selection and price congruence between online and offline stores. Thus, less corresponding change occurs in retail store attitude.

H3a Retail brand familiarity strengthens the relationship between online-offline product selection congruence and retail store attitude change.

$\mathrm{H} 3 \mathrm{~b}$ Retail brand familiarity strengthens the relationship between online-offline price congruence and retail store attitude change.

According to Keller ${ }^{[10]}$, secondary brand associations may be important if existing primary associations (derived from direct experience with the brand) are deficient in some way. When the retail brand familiarity is low, consumers' primary associations derived from direct experience with the traditional retailer's physical stores are deficient. Thus, secondary associations sourced from category attribute associations of online stores will play a more 
Table 1. The square root of average variance extracted and the correlations

\begin{tabular}{|c|c|c|c|c|c|c|}
\hline Variables & 1 & 2 & 3 & 4 & 5 & 6 \\
\hline 1. Online-offline product selection congruence & 0.832 & & & & & \\
\hline 2. Online-offline price congruence & $0.547^{* * * a}$ & 0.871 & & & & \\
\hline 3. Online-prototypical product selection congruence & $0.704^{* * *}$ & $0.562^{* * *}$ & 0.833 & & & \\
\hline 4. Online-prototypical price congruence & $0.493^{* * *}$ & $0.721^{* * *}$ & $0.709^{* * *}$ & 0.860 & & \\
\hline 5. Retail store attitude change & $0.523^{* * *}$ & $0.521^{* * *}$ & $0.563^{* * *}$ & $0.570^{* * *}$ & 0.854 & \\
\hline 6. Retail brand familiarity & $0.571^{* * *}$ & $0.455^{* * *}$ & $0.578^{* * *}$ & $0.499^{* * *}$ & $0.568^{* * *}$ & 0.871 \\
\hline
\end{tabular}

important role when low-familiarity consumers search or shop through the online store of a traditional retailer. In this situation, consumers are more likely to compare the online store of a traditional retailer with the prototypical online store since the latter possesses salient category attributes of online stores which may be transferred as secondary associations ${ }^{[3]}$. In other words, when the retail brand familiarity is low, consumers are more susceptible to attribute congruence between the online store of a traditional retailer and the prototypical online store. Accordingly, online-prototypical congruence orientation is deemed to have more capability to enhance the transference of category attribute associations as secondary associations from the prototypical online store to the retail brand, which leads to more positive change of retail store attitude. Conversely, when the retail brand familiarity is high, the formation of retail brand beliefs relies more on primary associations, and secondary associations are less important to consumers. Accordingly, the transference of category attribute associations caused by online-prototypical congruence orientation is less complete, thus leading to less corresponding change in retail store attitude.

$\mathrm{H} 4 \mathrm{a}$ Retail brand familiarity weakens the relationship between online-prototypical product selection congruence and retail store attitude change.

$\mathrm{H} 4 \mathrm{~b}$ Retail brand familiarity weakens the relationship between online-prototypical price congruence and retail store attitude change.

\section{METHOD}

Subjects from various types of online forums and online chat groups as well as the randomly selected samples of an independent market research company were invited to participate in the study by email or leaving an online message. Thirty-one land-based multichannel retailers were selected from Chinese top 100 retailers in 2013 as stimuli. Respondents followed a link to an online questionnaire. After screening the respondents to make sure that they had shopping experience in both store forms of one or more traditional retailers on the list, respondents were instructed to specify a multichannel retailer and complete the survey with respect to that retailer. A total of 726 responses were obtained. After deleting the invalid responses, 691 responses were used in the final data analysis. Among them, 218 from online forums, 164 from online chat groups and 309 from the market re-search company. The respondents included consumers from a variety of backgrounds (employees of the company account for $53.7 \%$, students account for $23.4 \%$, staffs of government and state-run institutions account for $17.4 \%$, and others account for $5.5 \%$; among them, females account for $52.1 \%$, males account for $47.9 \%$; average age is 28.5 years old). The items used for our measurement scales were based on empirically validated scales from previous studies $[3,6,13,19]$. We measured the questionnaire's constructs with seven-point Likert scales.

\section{RESULTS}

\subsection{Measurement model}

Confirmatory Factor Analysis (CFA) enables the performance of tests regarding the convergent validity, discriminant validity and reliability of the study constructs. The measures of overall fit mostly meet conventional standards, which suggests that our model fits the data well $\left(\chi^{2} /\right.$ d.f. $=2.756$, RMSEA $=0.053$, $\mathrm{SRMR}=0.020, \mathrm{GFI}=0.960, \mathrm{AGFI}=0.935, \mathrm{NFI}=0.987$, $\mathrm{RFI}=0.982$, NNFI $=0.989, \mathrm{CFI}=0.992$, IFI=0.992).

More specially, for all constructs, the composite reliability and coefficient alpha values exceed the threshold value of $0.6^{[20,21]}$. Therefore, the scale for the constructs appears to exhibit satisfactorily internal consistency reliability. All the factor loadings, which range from 0.783 to 0.882 , are significant $(\mathrm{p}<0.001)$, indicating that the convergent validity is achieved for all the study constructs. The discriminant validity of the construct measures was assessed on the basis of the Fornell and Larcker's ${ }^{[22]}$ criterion. Table 1 reports the square root of average variance extracted (AVE) and the correlations between all pairs of constructs. The diagonal elements are the square root of AVE, which are greater than the off-diagonal elements of mutual correlations, indicating that the discriminant validity is supported.

\subsection{Test of main effects}

We use AMOS to model the structural relationships 


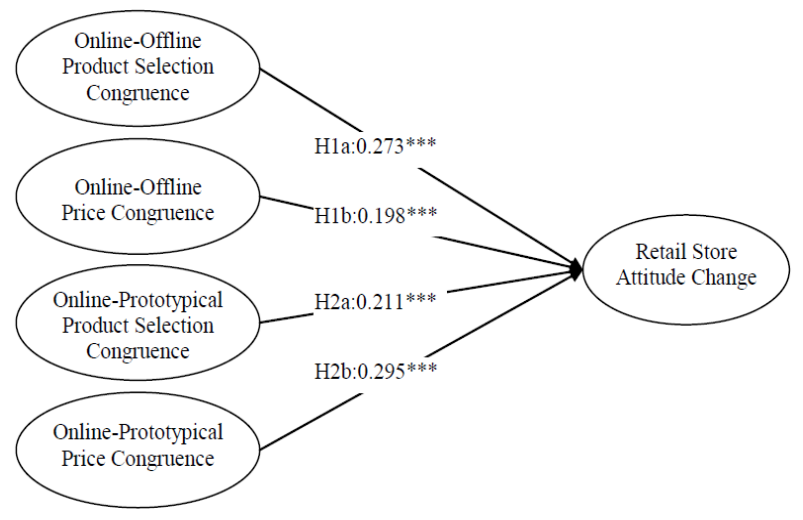

Figure 1. Conceptual framework

Table 2. Test results of moderating effects

\begin{tabular}{|c|c|c|c|c|c|}
\hline \multirow[t]{2}{*}{ Hypotheses } & \multirow[t]{2}{*}{ Paths } & \multicolumn{3}{|c|}{$\begin{array}{l}\text { Retail brand familiarity } \\
\text { Unstandardized Estimate } \\
\text { (T value) }\end{array}$} & \multirow[t]{2}{*}{ Conclusion } \\
\hline & & Low & High & $\Delta \chi^{2}$ & \\
\hline $\mathrm{H} 3 \mathrm{a}$ & $\begin{array}{l}\mathrm{O}-\mathrm{O}^{\mathrm{b}} \text { product selection congruence } \\
\rightarrow \text { Retail store attitude change }\end{array}$ & $0.134 *(2.170)$ & $0.309 * * *(4.638)$ & 2.866 & Not supported \\
\hline $\mathrm{H} 3 \mathrm{~b}$ & $\begin{array}{l}\text { O-O price congruence } \\
\rightarrow \text { Retail store attitude change }\end{array}$ & $0.041(0.817)$ & $0.231 * * *(4.828)$ & $4.895 *$ & Supported \\
\hline $\mathrm{H} 4 \mathrm{a}$ & $\begin{array}{l}\mathrm{O}-\mathrm{P}^{\mathrm{c}} \text { product selection congruence } \\
\rightarrow \text { Retail store attitude change }\end{array}$ & $0.233 * * *(3.428)$ & $0.081(1.411)$ & 3.884* & Supported \\
\hline $\mathrm{H} 4 \mathrm{~b}$ & $\begin{array}{l}\text { O-P price congruence } \\
\rightarrow \text { Retail store attitude change }\end{array}$ & $0.298 * * *(6.242)$ & $0.155 * *(2.800)$ & 2.208 & Not supported \\
\hline
\end{tabular}

$\mathrm{a}^{*}: p \leq 0.05{ }^{* *}: p \leq 0.01 ;{ }^{* * *}: p \leq 0.001 \quad{ }^{\mathrm{b}}$ O-O: Online-Offline ${ }^{\mathrm{c}}$ O-P: Online-Prototypical

posited by our conceptual framework (see Figure 1). The measures of overall fit mostly meet conventional standards, which suggests that our model fits the data well $\quad\left(\chi^{2} /\right.$ d.f. $=2.726, \quad$ RMSEA $=0.074, \quad$ GFI $=0.931$, AGFI $=0.882, \quad$ RFI $=0.904, \quad \mathrm{NFI}=0.930, \quad \mathrm{CFI}=0.954$, $\mathrm{IFI}=0.955, \mathrm{TLI}=0.933$ ). Figure 1 reports the parameter estimates of our basic model. The results confirm the positive effects of online-offline product selection congruence $(\gamma=0.273, \mathrm{t}=6.348)$, online-offline price congruence $(\gamma=0.198, \mathrm{t}=5.197)$, online-prototypical product selection congruence $(\gamma=0.211, \mathrm{t}=5.079)$ and online-prototypical price congruence $(\gamma=0.295$, $\mathrm{t}=6.546)$ on retail store attitude change, which support $\mathrm{H} 1 \mathrm{a}, \mathrm{H} 1 \mathrm{~b}, \mathrm{H} 2 \mathrm{a}$ and $\mathrm{H} 2 \mathrm{~b}$.

\subsection{Test of moderating effects}

We use multi-group analysis to test $\mathrm{H} 3-\mathrm{H} 4$, which refer to the moderating role of retail brand familiarity. First, we performed a median split along the values of the moderator variables to create two subsamples for each moderator, one with low values of the moderator and the other with high values. We then analysed the basic model implied by our theoretical framework simultaneously in both groups using AMOS. Table 2 shows the parameter estimates for the different subgroups.

The effect of online-offline product selection congruence on the retail store attitude change is stronger among consumers with a high level of retail brand familiarity $(\gamma=0.309, p<0.001)$ compared with low-familiarity consumers $(\gamma=0.134, \quad p<0.05)$. To statistically test the significance of this moderating effect, we relied on a chi-square difference test. The result shows that the chi-square difference with $\Delta$ d.f. $=1$ is not significant at the 0.05 level $\left(\Delta \chi^{2}=2.866\right)$ Thus, H3a is not supported. On the other hand, although the effect of online-offline price congruence on retail store attitude change is not significant $(\gamma=0.041$, n.s. $)$ among consumers with low level of retail brand familiarity, the effect becomes stronger and significant among high familiarity consumers $(\gamma=0.231, p<0.001)$. The chi-square difference is significant $\left(\Delta \chi^{2}=4.895, \Delta\right.$ d.f. $\left.=1, \mathrm{p}<0.05\right)$ in support of $\mathrm{H} 3 \mathrm{~b}$.

Our results indicate a stronger impact of online-prototypical product selection congruence on retail store attitude change among consumers with a low level of retail brand familiarity $(\gamma=0.233, p<0.001)$ compared with consumers with high retail brand familiarity $\left(\gamma=0.081\right.$, n.s., $\Delta \chi^{2}=3.884, \Delta$ d.f. $\left.=1, p<0.05\right)$ in support of H4a. The effect of online-prototypical price congruence on retail store attitude change becomes stronger among consumers with low retail brand familiarity $(\gamma=0.298, \mathrm{p}<0.001)$ compared with high-familiarity con-sumers $\quad(\gamma=0.155, \quad \mathrm{p}<0.01)$. 


\section{SHS Web of Conferences}

However, the chi-square difference is not significant at the 0.05 level $\left(\Delta \chi^{2}=2.208, \Delta\right.$ d.f. $\left.=1\right)$. Thus, H4b is not supported.

\section{DISCUSSION}

Our finds support the view that product selection and price congruence across stores can improve retail store attitude; however, both the orientations of online marketing strategies and the consumer characteristics must be considered. Online-offline product selection congruence and online-prototypical price congruence have significant effects on retail store attitude change whenever retail brand familiarity is high or low. Only when retail brand familiarity is high, online-offline price congruence exerts a positive and telling effect on retail store attitude change. On the other hand, the positive effect of online-prototypical product selection congruence on retail store attitude change is significant only among consumers with low retail brand familiarity.

Therefore, when the retail brand familiarity is low, online stores of traditional retailers should balance both orientations (i.e. keep an appropriate level of each orientation) in product selections and adopt "pursuit of ideal" in pricing strategy. When the retail brand familiarity is high, the "retention of tradition" should be considered in product selections and both orientations should be integrated in pricing strategy.

\subsection{Managerial implications}

First of all, our studies show that to improve the retail store attitude, retail managers should adopt a customer-oriented perspective that takes the psychologies of their targeted customers into consideration in online channel extension. Many traditional retailers launched online marketing programs based on the motivation to strengthen offline channel and take the online channel as an appendage to traditional bricks and mortar or a media of advertisement. However, the psychological characteristics of customers are often ignored. Since inner psychological characteristics affect the way a person responds to their environment ${ }^{[11]}$, consumers with different psychological characteristics may make different responses to external marketing stimuli. Traditional retailers who adopt a customer-oriented approach may attach more attention to consumers' psychological characteristics and then take properly corresponding measures, thus achieving a real improvement in retail store attitude.

Second, when traditional retailers expect to keep the loyalty of customers with high retail brand familiarity through online channel extension, online stores of these retailers should adopt "retention of tradition" in product selections while integrating both orientations in prices. High familiarity customers' attitudes toward the retail brand are likely to be improved by factors as follows: (1) similar product selections and prices between the traditional retailer's online and offline stores; (2) consistent prices between the traditional retailer's online store and the prototypical online store. Thus, traditional retailers could integrate both orientations in prices by two approaches: (1) offering the same prices for the same items across online and offline channels (i.e. a product/price integrity strategy) ${ }^{[2]}$; (2) pricing their online salable items by reference to prototypical online stores. Moreover, traditional retailers should ensure that their online stores highly overlap with their physical stores for the products featured offline ${ }^{[5]}$.

Third, our results suggest that when traditional retailers intend to attract new customers with low retail brand familiarity through online channel extension, online stores of these retailers should adopt "pursuit of ideal" in pricing while keeping a balance between "retention of tradition" and "pursuit of ideal" (i.e. the appropriate level of each orientation) in product selections. Low-familiarity customers' attitudes toward the retail brand are likely to be improved by factors as follows: (1) similar product selections and prices between the traditional retailer's online store and the prototypical online store; (2) the product overlap between the traditional retailer's online and offline stores. Thus, online stores of traditional retailers could balance both orientations in product selections by two approaches: (1) Introduce new products which are salable in the prototypical stores to strengthen the superiority of their product selections; (2) maintain existing products featured offline to create more opportunities of cross-channel shopping for consumers, such as online search and offline experience/purchase, or offline experience/ examination and online purchase. Moreover, online stores of traditional retailers should keep their price levels consistent with those of prototypical online stores to meet consumers' needs for "saving money."

\subsection{Limitations and future research}

Although the present study furthers the knowledge on strategy choice of retailer channel extension, some limitations still occur. First, the study only identifies the moderating role of retail brand familiarity. Future research may consider other consumer characteristics and shopping contexts (such as utilitarian and hedonic shopping orientation, time pressure). Second, we explore only two types of store attributes: product selection and price. Future research could address other store attributes (e.g. service quality, shopping atmosphere and store design) to investigate how other types of store attribute congruence improve the retail store attitude. Third, only direct effects of online marketing orientations on retail store attitude change are examined. No evidence is provided regarding the concrete modification of retail brand knowledge 
schema in this process. Therefore, applying some mediators (e.g. retailer awareness, retailer perceived quality and retailer associations) ${ }^{[23]}$ to explain the mechanism of strategy on performance in this context are encouraged.

\section{ACKNOWLEDGEMENT}

This work was supported by National Natural Science Foundation of China (71172002).

\section{REFERENCES}

[1] Nelson, A. J. \& Leon A. 2012. Bricks and clicks: rethinking retail real estate in the e-commerce era Report, RREEF Real Estate, Deutsche Bank Group.

[2] Neslin, S. A. \& Shankar V. 2009. Key issues in multichannel customer management: current knowledge and future directions. Journal of Interactive Marketing, 23(1): 70-81.

[3] Badrinarayanan, V., Becerra, E. P., Kim, C. H. \& Madhavaram, S. 2012. Transference and congruence effects on purchase intentions in online stores of multi-channel retailers: initial evidence from the U.S. and South Korea. Journal of the Academy of Marketing Science, 40(1): 539-557.

[4] Teltzrow, M., Meyer, B. \& Lenz, H. J. 2007. Multichannel consumer perceptions. Journal of Electronic Commerce, 8(1): 18-31.

[5] Berman, B. \& Thelen, S. 2004. A guide to developing and managing a well-integrated multi-channel retail strategy. International Journal of Retail \& Distribution Management, 32(3): 147-156.

[6] Laroche, M., Kim, C. K. \& Zhou, L. X. 1996. Brand familiarity and confidence as determinants of purchase intention: an empirical test in a multiple brand context. Journal of Business Research, 37(2): 115-120.

[7] Campbell, M. C., \& Keller, K. L. 2003. Brand familiarity and advertising repetition effects. Journal of Consumer Research. 30(2): 292-304.

[8] Thorbjørnsen, H. 2005. Brand extensions: brand concept congruency and feedback effects revisited. Journal of Product and Brand Management, 14(4): 250-257.
[9] Canli, G. Z. \& Maheswaran, D. 1998. The effects of extensions on brand name dilution and enhancement. Journal of Marketing Research, 35(4): 464-473.

10] Keller, K. L. 1993. Conceptualizing, measuring, and managing customer-based brand equity. Journal of Marketing, 57(1): 1-22.

[11] Schiffman, L. G. \& Kanuk, L. L. 1995. Consumer Behavior (9th ed.). Upper Saddle River, NJ: Pearson Education.

[12] Wilkie, W. 1986. Consumer Behavior. New York: John Wiley \& Sons.

[13] Spears, N. \& Singh, S. N. 2004. Measuring attitude toward the brand and purchase intentions. Journal of Current Issues and Research in Advertising, 26(2): 53-66.

[14] Dwivedi, A., Merrilees, B. \& Sweeney, A. 2010. Brand extension feedback effects: a holistic framework. The Journal of Brand Management, 12(5): 328-342.

[15] Kwon, W. S. \& Lennon, S. J. 2009. Reciprocal effects between multichannel retailers' offline and online brand associations. Journal of Retailing, 85 (3): 376-390.

16] Hartman, K. B., \& Spiro, R. L. 2005. Recapturing store image in customer-based store equity: a construct conceptualization. Journal of Business Research. 58(8): $1112-1120$

[17] Sujan, M. 1985. Consumer knowledge: effects on evaluation strategies mediating consumer judgments. Journal of Consumer Research, 1(12): 31-46.

[18] Alba, J. W. \& Hutchinson, J. W. 1987. Dimensions of consumer expertise. Journal of Consumer Research, 13 (3): 411-454.

[19] Gefen, D. 2000. E-commerce: the role of familiarity and trust. Omega, 28(6): 725-737.

[20] Bagozzi, R. P. \& Yi, Y. 1988. On the evaluation of structural equation models. Journal of the Academy of Marketing Science, 16(1): 74-94.

[21] Nunnally, J. C. \& Bernstein, I. H. 1994. Psychometric Theory (3rd ed.). New York: McGraw-Hill.

[22] Fornell, C. \& Larcker, D. F. 1981. Evaluating structural equation models with unobservable variables and measurement error. Journal of Marketing Research, 18 (2): $39-50$.

[23] Wu, J. F. \& Tian, Z. L. 2009. The impact of selected store image dimensions on retailer equity: evidence from 10 Chinese hypermarket. Journal of Retailing and Consumer Services, 16 (6): 486-494. 